\title{
COMPLICATIONS AFTER OPERATION FOR OESOPHAGEAL ATRESIA*
}

\author{
BY \\ F. REHBEIN and F. YANAGISWA \\ From the Surgical Department of the Children's Hospital, Bremen
}

Although certain advances have been made in the treatment of oesophageal atresia, there are still many problems we have to deal with. However many mistakes we learn to avoid, the possibility of complications, which may endanger a successful outcome, is still present. Gertz and Winkel Smith (1958) have already pointed out that the airing of problems is of great importance and it therefore seems justified to give a short review of the complications encountered in our patients.

It is only in the last three years that we have used the transpleural approach. In suturing we followed first the technique of Haight and Towsley (19.43), Gross (1953), Swenson (1947) and others, but for two years we have preferred to use the following procedure (Fig. 1): two single stitches are inserted, and then one continuous posterior suture which is tied to the single stitches. Then the feeding tube is placed in position and the anterior wall closed with interrupted stitches. Normally we start feeding through the tube at the third day, but in cases of suture with tension we delay it till the seventh or eighth day. If tension is severe we perform a gastrostomy and also a jejunostomy.

From 1951 to 1958 we operated on 84 cases (Table 1). Eight cases which were moribund on admission or cases where only a gastrostomy was done are not included in this summary. I will come back later to the four cases without fistula, all of which died. Out of 64 anastomoses 37 survived the operation; two children died several weeks later; the remaining 35 are alive. Closure of the fistula alone without anastomosis was unsuccessful in every case. In cases where there was a wide distance between the two segments we tried to join them, using a rubber tube as a prosthesis. This technique was successful only in one case. At autopsy we could see that the distance was covered by granula-

* A paper read at a meeting of the British Association of Paediatric Surgeons held in London in July, 1958. tion tissue, and in some cases by an epithelial layer of tissue as well. In all cases except one the tracheal-fistula had opened up. In this one case kinking of the oesophagus and fistula into the surrounding tissue had occurred (Fig. 2). Four months later this area was resected and anastomosis was performed. The latter treatment was difficult because of severe stricture.

In the recent literature mistakes and complications are often mentioned, for example by Humphreys, Hogg and Ferrer (1956), Shaw, Paulson and Siebel (1955) and particularly by Gertz and Winkel Smith (1958). Because complications in cases of anastomosis are the most interesting and also from the practical point of view the most important ones, I will only discuss our 64 anastomosed cases (Fig. 3). Out of 29 deaths 13 died of respiratory complications, 10 of suture insufficiency and recurrent fistula, and six died of other causes. This summary can only give a limited picture, because it is very rare to find that one factor alone leads to complications or death. Table 2 shows how far, for instance, the birthweight was of importance. Some of the cases died because of our lack of experience in the early years. More recently the mortality rate shows an improvement (Table 3 ).

The most important factors in causing death are respiratory tract complications. Quite often, on admission, atelectasis is found which can be

TABLE 1

CASES OF OESOPHAGEAL ATRESIA (1951-1958)

\begin{tabular}{|c|c|c|c|c|}
\hline & & Number & Survivors & $\underset{(\%)}{\text { Mortality }}$ \\
\hline $\begin{array}{l}\text { With Fistula: } \\
\text { Anastomosis } \\
\text { Prosthesis (rubber tube) } \\
\text { Closure of fistula only } \\
\text { Without Fistula } \\
\text { W }\end{array}$ & $\begin{array}{l}\cdots \\
\cdots \\
\cdots \\
\cdots\end{array}$ & $\begin{array}{r}80 \\
64 \\
9 \\
7 \\
4\end{array}$ & $\begin{array}{r}38 \\
37 \\
1 \\
- \\
\end{array}$ & $\begin{array}{r}52 \\
43 \\
89 \\
100 \\
100\end{array}$ \\
\hline Total $\ldots$ & $\ldots$ & 84 & 38 & 54 \\
\hline
\end{tabular}



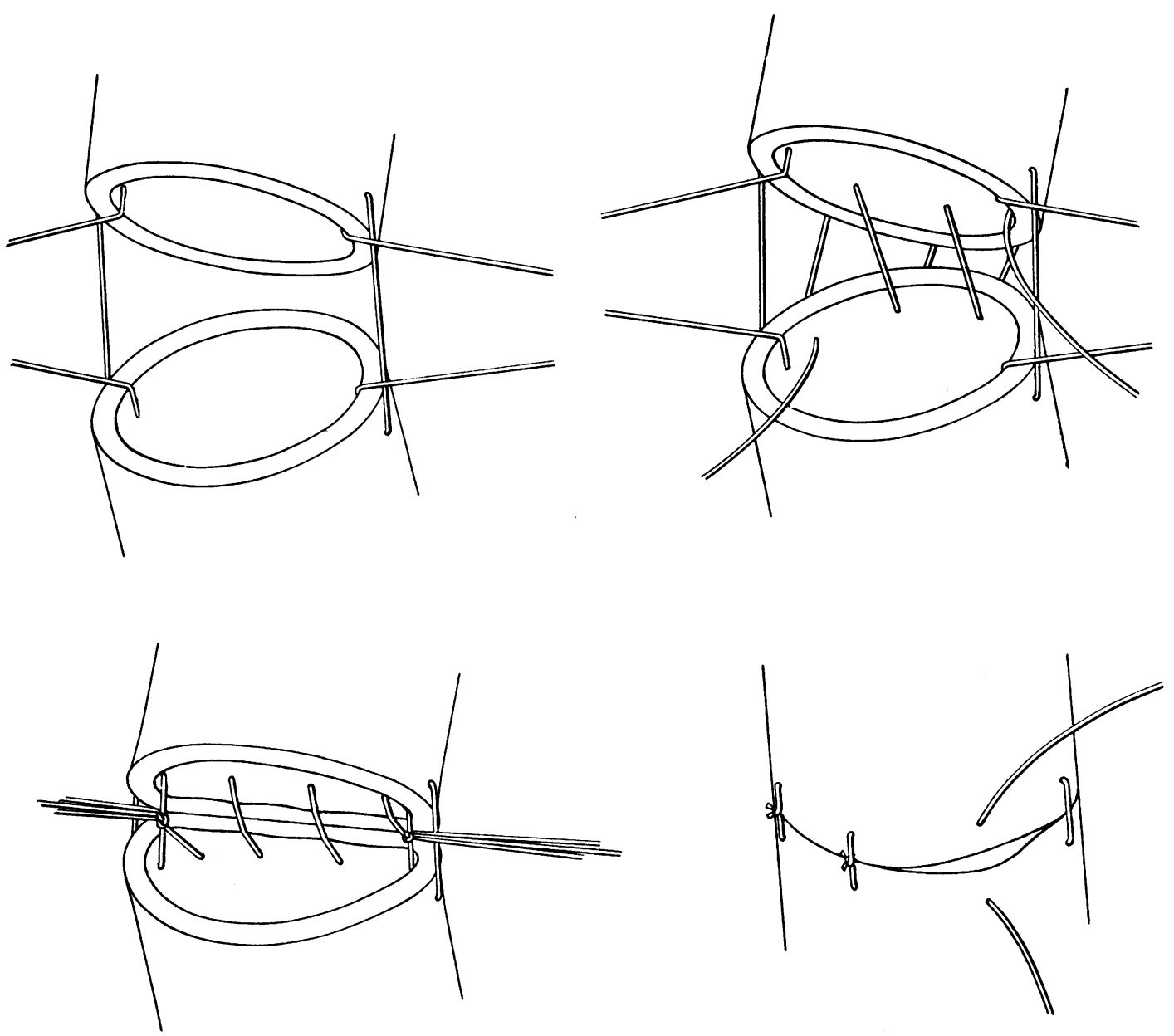

Fig. 1.-Suturing technique in oesophageal atresia.

improved or cleared up by intensive treatment. Post-operatively very often there is a large amount of secretion which leads to atelectasis and pneumonia if it is not aspirated. So it was in the majority of the 13 cases. This secretion starts on the second post-operative day and ends usually on the fourth day. Some children did not need any

TABLE 2

BIRTHWEIGHT RELATED TO RESULT OF OPERATION (64 ANASTOMOSES)

\begin{tabular}{|c|c|c|c|c|}
\hline $\begin{array}{l}\text { Weight } \\
\text { (g.) }\end{array}$ & & Number & Survivors & $\begin{array}{c}\text { Mortality } \\
(\%)\end{array}$ \\
\hline $\begin{aligned}<2,000 \ldots \\
2,000-2,500 \\
>2,500 \ldots\end{aligned}$ & $\begin{array}{ll}. & . . \\
\cdots & . .\end{array}$ & $\begin{array}{r}4 \\
27 \\
33\end{array}$ & $\begin{array}{l}\overline{12} \\
23\end{array}$ & $\begin{array}{r}100 \\
56 \\
30\end{array}$ \\
\hline
\end{tabular}

suction, others had to be aspirated as often as three times in 24 hours. To decide if and when suction is necessary can be done in many cases only by watching the respiration. The frequency and the type of breathing are important points as well.

TABLE 3

CASES OF OESOPHAGEAL ATRESIA WITH TRACHEOOESOPHAGEAL FISTULA (1951-1958)

\begin{tabular}{rr|r|r|r}
\hline \multicolumn{1}{c|}{ Year } & Number & Survivors & $\begin{array}{c}\text { Mortality } \\
(\%)\end{array}$ \\
\hline $1951-1953$ & & 16 & 6 & 63 \\
1954 &. & 10 & 2 & 80 \\
1955 &. & 12 & 2 & 83 \\
1956 &. & 8 & 4 & 50 \\
1957 &. & 24 & 17 & 29 \\
1958 &. & 10 & 7 & 30 \\
\hline Total &. & 80 & 38 & 53 \\
\hline
\end{tabular}


Atelectasis of smaller portions of lung can usually be cleared up quite easily. A total atelectasis of one lung we could not clear up. If pneumonia was already present following atelectasis and if induration of the lung was found at operation and the lung did not collapse, the results were poor.

Tracheotomy has been performed altogether only

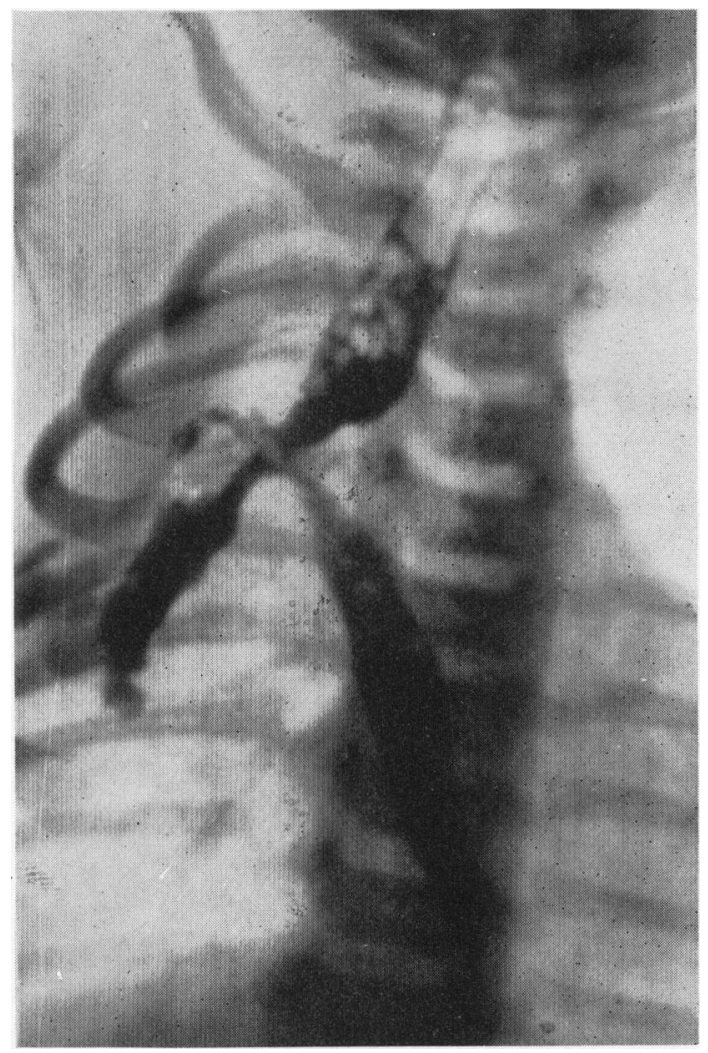

FIG. 2.-Kinking and fistula formation after approaching the oesophageal segments using a rubber tube as a guide. Healing after resection and suture.

four times in the last two years. In three cases it was necessary shortly after the operation because of severe difficulty in breathing and deep cyanosis. In spite of the stridor and cyanosis that two children showed even before operation it is presumed that endotracheal intubation caused some swelling of the mucous membranes. In one child there was so much secretion that as late as on the eleventh postoperative day a tracheotomy had to be done. All four children withstood the procedure well and we think that they were saved by it. On three occasions we had considerable difficulty in removing the tracheotomy tube. We finally succeeded after several attempts and with the help of laryngeal intubation.

Suture insufficiency and recurrent fistula can happen independently. The reopening of the tracheal fistula alone is supposedly more rare. It is due primarily in most of the cases to insufficiency of anastomosis, and local inflammation and abscess formation. This complication occurred 13 times in our 64 anastomoses. Only three of the 13 cases survived.

In one child who was operated on by the extra pleural approach we noticed leakage of air and

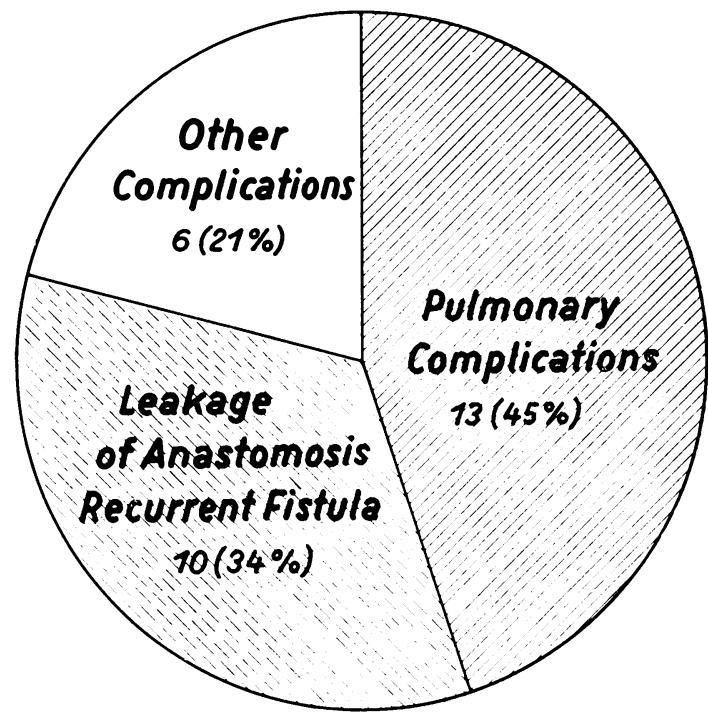

Fig. 3.-Causes of death in 29 cases (from 64 anastomoses).

contrast medium into the retropleural space on the eighth day. There was spontaneous healing.

Our first case, who is 7 years old now, had a wide suture breakdown with leakage of food into the mediastinum and then a recurrent fistula. This fistula closed up spontaneously during the next few months. Now there is still a small diverticulum in this area and the oesophagus is narrowed in one place. But the boy has no difficulty in eating and is normally developed (Fig. 4).

There were no complications at first in the third case operated on by transpleural approach. But with the start of oral feeding 14 days after the operation he suffered from coughing spells, cyanosis and abdominal distension. Radiographic examination showed a recurrent fistula. We succeeded in saving the child's life by gastrostomy and jejunal 


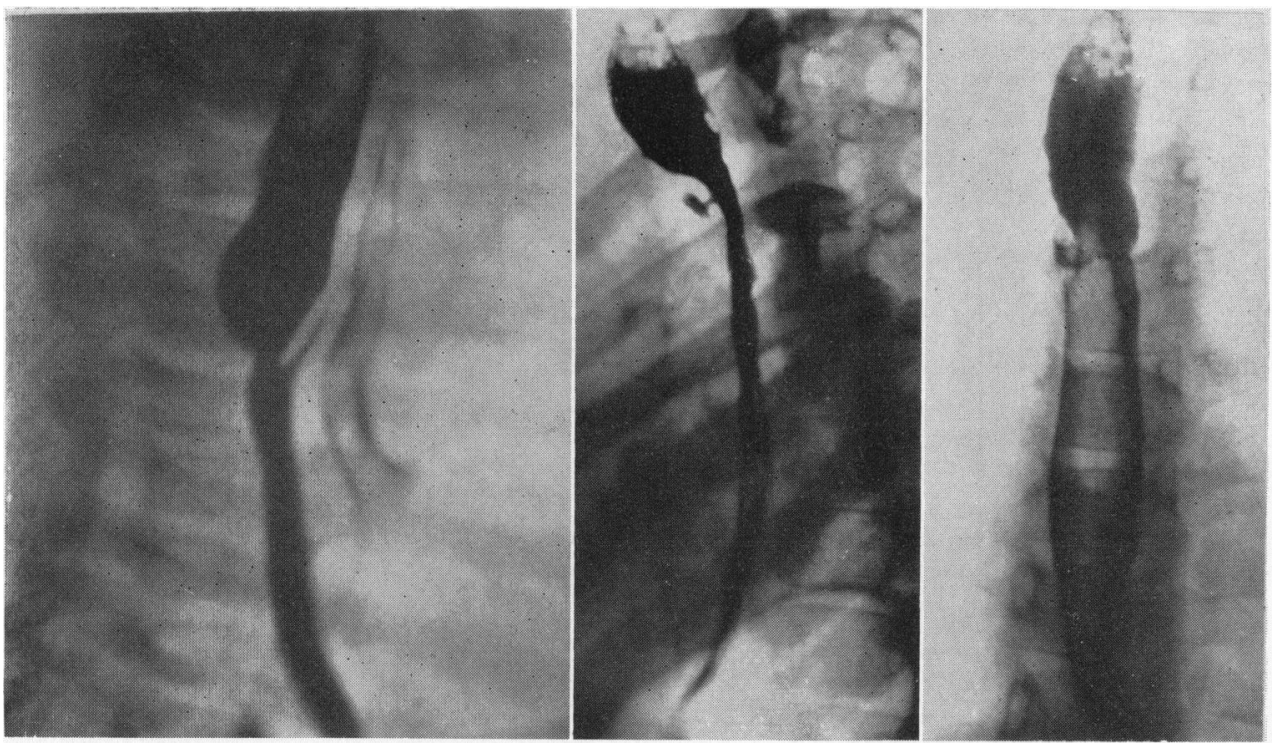

FiG. 4.-Formation of an oesophago-tracheal fistula after operation for atresia. Spontaneous healing with formation of a small diverticulum.

feeding. In spite of these measures, severe aspirations continued which retarded the child's development. Finally, at the age of 9 months, we did the second operation (Figs. 5 and 6).

A few cases where pneumothorax occurred died. Efforts to avoid aspiration by jejunal feeding in cases of insufficiency with recurrent fistula were unsuccessful except in the one case mentioned above. So we really should follow the suggestion of Shaw et al. (1955) and, in certain cases of suture breakdown with recurrent fistula, try as soon as possible a second suturing. According to his report Shaw was successful in a few early second operations. Success or misfortune will depend on how far there is already inflammation or abscess formation in the mediastinum. Lethal suture breakdown we only saw twice in our last 30 anastomoses. The cause of its frequent occurrence in the earlier years was probably insufficient preparation of the two parts of the oesophagus. Maybe the occurrence of suture breakdown is less dangerous when using the extrapleural approach, but in spite of that the transpleural approach is to be preferred. If there are signs of leaking at the second or third day after operation there is probably a gap between the stitches. The early leak is especially dangerous, because then no adhesions have been formed.

Among our cases we found a large number of cardiovascular defects, but in most of these cases no anastomosis could be performed. Among the
29 deaths six died of other complications (Table 4). One child died six weeks and another one 10 weeks after operation; in both cases the anastomosis had entirely healed. In the next case we diagnosed a concomitant duodenal atresia too late; here also the anastomosis was nearly healed. I just want to mention that in another child with duodenal atresia we found an extensive rupture of the stomach. In the third case a peritonitis following colostomy led to death. The last two children died of uraemia because of bilateral atresia of the ureter. Here death can only be attributed to this concomitant malformation. Three weeks after operation another child suffered from severe diarrhoea due to a necrotizing ileitis. The child's condition deteriorated rapidly, but it finally withstood the resection of the gangrenous bowel loop.

The causes of death of the four children without tracheo-oesophageal fistula are shown in Table 5.

We saw severe stenosis in two cases. These children had to stay in hospital for months and had to have intensive dilatation therapy with bougies.

TABLE 4

OTHER CAUSES OF DEATH

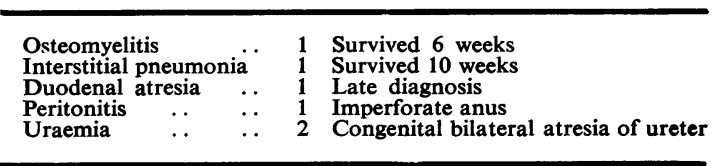




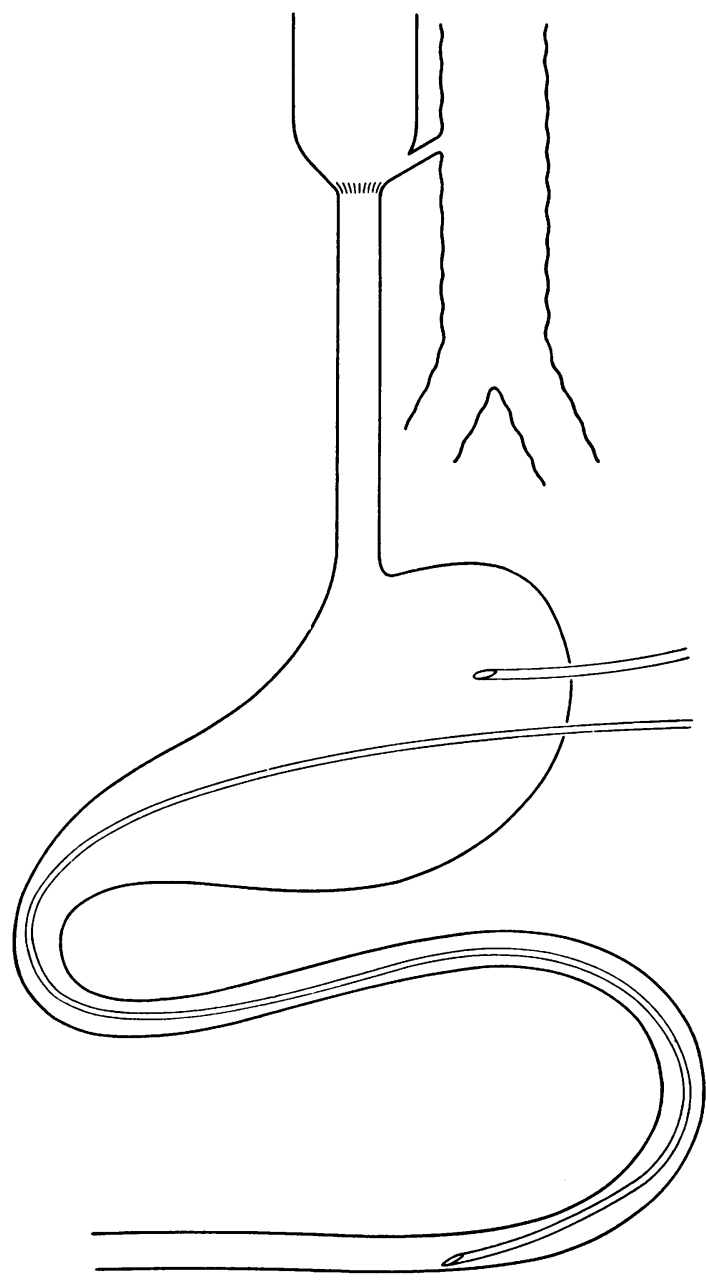

FIG. 5.-Gastrostomy and jejunal feeding in recurrent fistula.

In one child, suddenly, two months after operation, an occlusion occurred at the suture line. In the radiograph it looked like an unoperated case

\section{TABLE 5}

CAUSES OF DEATH IN FOUR CASES OF OESOPHAGEAL ATRESIA WITHOUT TRACHEO-OESOPHAGEAL FISTULA

(1) Peritonitis from decubitus by feeding tube

(2) Peritonitis originating from gastrostomia

(3) Death during attempt to pull stomach up to upper part of oesophagus (mongol)

(4) Arrest of breathing by compression of trachea during transposition of large bowel (age 16 months)

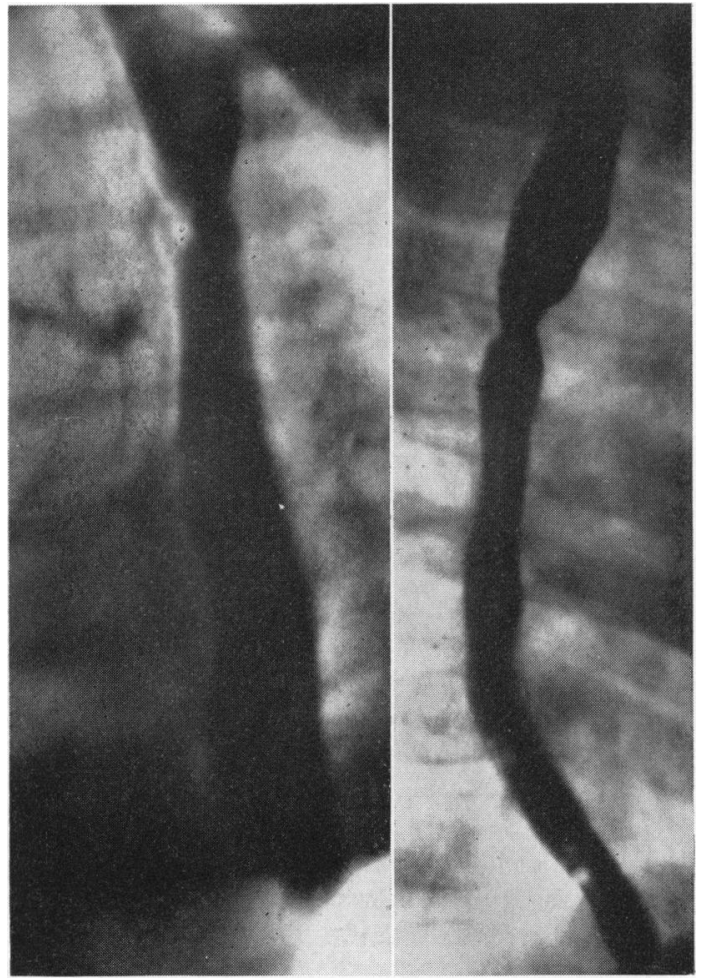

Fig. 6.-Recurrent fistula. Healing after second operation.

(Fig. 7). We performed a gastrostomy at once. With the help of a thread we pulled bougies of increasing diameter through the stricture. Now the child is a little over a year old and has no remaining difficulty in swallowing. Slight degrees of stenosis occur more frequently, so every child gets dilatation as a routine before discharge. Frequently there are some difficulties in swallowing which can be treated easily at the age of 6 to 8 months when the food becomes more solid. In one child with recurrent aspirations a grape got stuck at the suture site and had to be removed by oesophagoscopy. In another case it was a coin that had to be removed. We have 


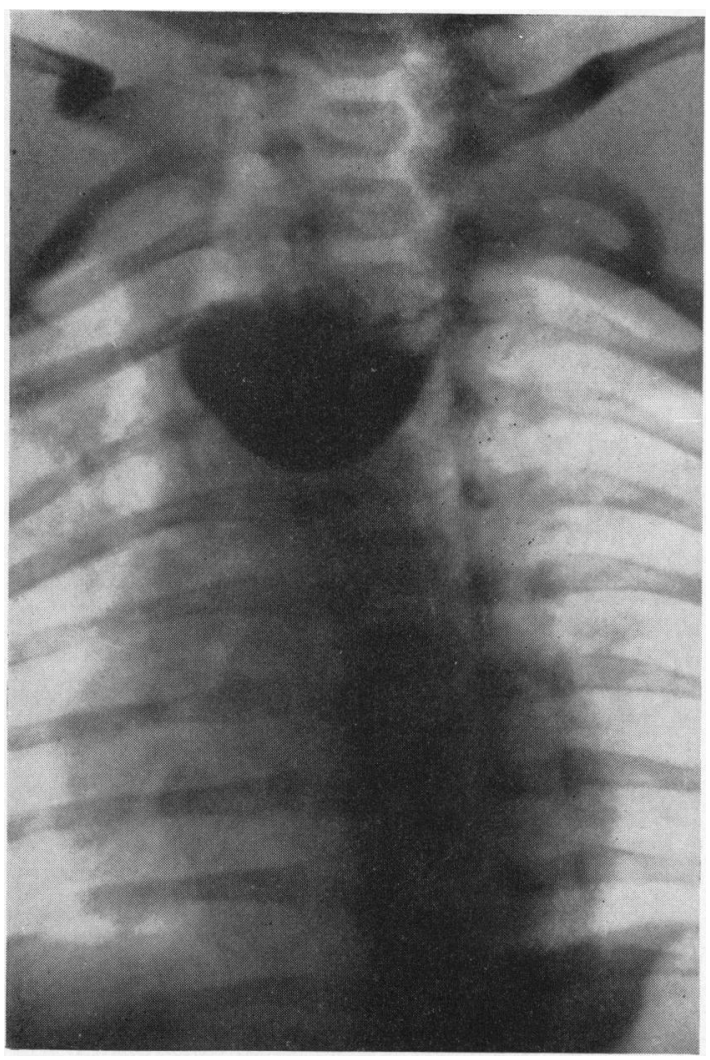

Fig. 7.-Severe stenosis two months after-operation. rarely needed to perform a gastrostomy during the last few years. In cases of severe stenosis gastrostomy is of help, as also in cases with severe aspiration.

The statistics of all those who have published the results of operating on cases with oesophageal atresia show that with growing experience the mortality rate is reduced. By improving our operative technique the number of cases in which at one time we thought joining would not be possible has become less and less. By improvement of suturing technique the number of breakdowns has also diminished. It is quite possible also that where breakdown occurs some of the cases can be saved by early repair.

Lung complications can be reduced by adequate pre- and post-operative treatment. Tracheotomy will also help to improve the final results. Deaths caused by electrolyte and fluid imbalance can be avoided.

A certain number of deaths due to inanition, cerebral bleeding, concomitant malformation and late diagnosis are inevitable and will always remain.

\section{REFERENCES}

Gertz, T. C. and Winkel Smith, C. C. (1958). Dan. med. Bull., 5, 18. Gross, R. E. (1953). The Surgery of Infancy and Childhood.

Saunders, Philadelphia.
Haight. C. and Towsley, H. A. (1943). Surg. Gynec. Obstet., 76, Humphreys, G. H., Hogg, B. M. and Ferrer, J. (1956). J. thorac. Surg., 32, 332.

Shaw, R. R., Paulson, D. L. and Siebel, E. K. (1955). Ann. Surg., 142, 204.

Swenson, O. (1947). Surgery, 22, 324. 